This is the author's accepted manuscript version of a chapter that appears in Modern Studies in Property Law, Volume 8 published in 2015 by Hart Publishing.

Doi: 10.5040/9781782257776.ch-017

\title{
Registered Title and the Assurance of Reliability
}

\author{
Simon Cooper
}

\section{Introduction}

The defining feature of systems for registration of title is, of course, that the information about title displayed by the register is in some sense reliable. But reliability need not be seen as a quality of the information itself in the abstract. Systems for registration of title have been designed to serve a variety of social goals and so the reliability of the information in the register may need to be assured only to the restricted classes of person necessary to fulfil the particular social goal that motivated the registration law. The English version of registration is noteworthy for the convoluted means by which it indicates who gets the benefit of the assurance of reliability as well as for the opaque motivations underlying the choice of the particular class of persons in whose favour the assurance of reliability is given.

The English land registration system, like many others, famously emerged as a response to the difficulties and uncertainties troubling the investigation of title to land $^{1}$ and therefore its key component is a provision which gives a categorical assurance to a purchaser about the state of title that he will receive if the correct steps are followed. Since their first introduction, all of the English registration statutes have afforded at least this minimum protection: in favour of a prospective purchaser who inspects the register, and on the strength of it proceeds with the purchase and becomes proprietor, the system guarantees that the former proprietor had the ability to transfer an unimpeachable title in accordance with the registered entry. By such a strategy, the register deems a good root of title in the person named as proprietor and, subject to interests which override the register, allows the prospective acquirer to rely on the register as an accurate indicator of what he will receive from the seller. That is the minimum necessary for a workable system in which register entries are to take the place of inconclusive deeds and oaths as proof of title.

But it seems that there is much more to the English model of registration than protection for purchasers. Its assurance of reliability appears to be given to a far wider class of persons than is necessary to protect prospective purchasers who rely on the register in anticipation of a dealing. The assurance of reliability also appears to operate in favour of those who had no acquisitive intention. For example, it will be shown below that if a person is wrongly registered as proprietor by an internal registry

1 'Second Report of the Commissioners Appointed to Inquire into the Law of England respecting Real Property' (1830, H.C.P. xi.1), p.18; 'Report of the Commissioners Appointed to Consider the Subject of the Registration of Title with Reference to the Sale and Transfer of Land' (1857, c.2215), p.8; 'Report of the Royal Commissioners Appointed to Inquire into the Operation of the Land Transfer Act' (1870, c.20), para. 64. 
error, then the law allows him to keep the land or compensation for its loss even if he never expected to acquire the land and even if he was unaware of his new status until he received notification of the proceedings to reverse the error. That provides an assurance of reliability which goes far beyond the level necessary to encourage prospective purchasers to rely on the register. It is significant because the assurance of reliability, however broad or narrow, comes with associated burdens.

Whenever the register content is made reliable, it is accompanied by the possibility that an erroneous entry will be preserved in order to fulfil the commitment to reliability. This causes immediate sources of disadvantages for actors in the registration system: it increases the risk that the former owner will lose his property and it increases the burden on the indemnity fund contributors due to the ensuing compensation claim. The assurance of reliability is therefore suited to a cost-benefit assessment. In respect of its application to prospective purchasers, those disadvantages are suffered for a social benefit that has long been regarded as compelling: it is the foundation of cheap and secure conveyancing, eliminating the ancient source of delay in investigating title, and removing uncertainties in the root of title. Yet even when pursuing these worthy objectives, the assurance of reliability has recently come under scrutiny and experienced a degree of retrenchment in the case law: restricting the statutory vesting provision to a bare legal title ${ }^{2}$, expanding the overriding interests ${ }^{3}$, rectifying the register against a good faith purchaser ${ }^{4}$, qualifying the register by using off-register material as an aid to interpretation ${ }^{5}$, upholding a restrictive approach towards issuing guaranteed titles. ${ }^{6}$ At a time when even the protection of purchasers is reined in, how much more difficult it is to substantiate any assurance of reliability in favour of other persons whose interests were not expressed to be the motivation for introducing registration of title.

This chapter responds to the issue by examining the English land registration system and the privileged class to whom it extends the assurance of reliability. It identifies who is covered by the extended form of the assurance of reliability, it explores what potential social policy objective might justify extending the assurance of reliability to them, and how well the policy objective is being implemented. There are sound reasons for pursuing this inquiry. An understanding of the policy behind the extended assurance of reliability is essential as a precursor to any effective evaluation of its merits and the extent to which it justifies the disadvantages noted earlier, and it would better equip legal scientists and reformers to make an appraisal of whether current legislative rules effect a satisfactory means of implementation. An explicit articulation of the policy should assist in a purposive interpretation of the provisions of the legislation concerning the guarantee of title. It is also important for the study of the English registration system in comparative perspective: the approach to the

2 Fitzwilliam v Richall Holdings Services Ltd [2013] EWHC 86; A Goymour, 'Mistaken Registrations of Land' [2013] CLJ 617, A Nair, 'Forgery and the Land Registration Act 2002' (2013) 24 KLJ 403.

3 E.g. Link Lending Ltd v Bustard [2010] EWCA Civ 424; B Bogusz, 'The Relevance of "Intentions and Wishes" to Determine Actual Occupation' [2014] Conv 27. Chaudhary v Yavuz [2013] Ch 249; B McFarlane, 'Eastenders, Neighbours, Upstairs Downstairs' [2013] Conv 74.

4 Knights Construction (March) Ltd v Roberto Mac Ltd [2011] EWLandRA 2009/1459; E Lees, 'Title by Registration: Rectification, Indemnity and Mistake and the Land Registration Act 2002' (2013) 75 MLR 62.

$5 \quad$ Cherry Tree Investments Ltd v Landmain Ltd [2013] Ch 305 (Arden LJ, dissenting); P Butt, 'The Interpretation of Easements' in N Gravells, Landmark Cases in Land Law (Hart 2013 Oxford) p 33.

$6 \quad R($ Diep $) v$ Land Registry [2010] EWHC 3315; M Dixon, 'Editor's Notebook' [2011] Conv 1. 
reliability of the register and its underlying policy is vital to its functional classification and the viability of any cross-border transplants.

Those issues will be examined by reference to the rules which provide for the register to be rectified in the event of a mistake. If the register is susceptible to being rectified, its reliability is inevitably put in jeopardy and it is only through the associated rules which provide for individuals to resist rectification and claim state compensation that a degree of reliability can be salvaged. It is these rules which are the focus of this chapter. It regards the assurance of reliability as being provided where either (a) the individual is immune from rectification, (b) the individual is afforded an opportunity to be heard to resist the proceedings for rectification and the tribunal refuses rectification, or (c) the register is rectified but the individual is eligible for state compensation.

The chapter proceeds as follows. The first step is to identify the statutory provisions and indicative case law which demonstrate the range of persons to whom the assurance of reliability is extended. That will lead to a proposed explanation of the policy underlying the provisions. It is argued that the explanation for the extended scope of reliability lies in the protection of expectations that have been induced by the register. The next section then considers how this seemingly trite conclusion is obscured by its embodiment in rules which constitute a poorly aligned proxy for the underlying policy and thus contribute to the impression that the case law diverges from any coherent policy. Finally, the chapter examines the arguments which justify imposing potential limits to the extended scope of reliability.

\section{Extending Reliability beyond Prospective Purchasers}

It is beyond question that a registration system which was motivated by facilitating conveyancing and introducing certainty to titles must make the register reliable in favour of prospective purchasers who use the information to influence a decision to purchase. But it is far from self-evident that the system should make the register reliable in other circumstances; for example, where a prospective donee inspects it before deciding whether to accept or reject a gift, or where a registered proprietor examines his own title to confirm the detail of his own holdings before taking action. To address these concerns, this part will investigate the extent to which the English system makes the register reliable beyond the remit of protecting purchasers and why it might do so.

\section{A. The Scope of Protection against the Reversal of Mistakes}

The lack of authoritative instruction on the purpose behind the rectification and indemnity clauses means that normal technique of research into the travaux préparatoires does not yield sufficiently detailed information of the parliamentary intention and it is necessary to adopt the circuitous technique of making inductive inferences from the statutory text as applied in the cases.

Under the English model, register reliability is achieved through a variety of techniques. First, the estate vests in the person who becomes registered proprietor. ${ }^{7}$ Second, an unrecorded limitation cannot be the basis for questioning the title of a registered disponee. ${ }^{8}$ Third, an unprotected precarious interest cannot be enforced

Land Registration Act 2002, s 58(1).

LRA 2002, ss 23 and 26. 
against a registered transferee for value. ${ }^{9}$ These three techniques are relatively crude and the introduction of any sophistication or subtlety is left to the fourth technique, which is the focus of this chapter: in the event of a mistake in the register, a later acquirer receives protection in the event of a claim to rectify the mistake. ${ }^{10}$ The acquirer's protection is expressed by allowing the acquirer the opportunity to resist any claim for rectification and the losing party is eligible to claim state indemnity. It is not yet settled whether the protection arises from an absolute jurisdictional bar on rectifying against a registered disponee for value ${ }^{11}$, or whether it is manifested merely in the judicial reluctance to exercise the discretionary rectification power in such circumstances, ${ }^{12}$ but in the case of an adverse exercise of discretion against a later acquirer, protection would be expected in the form of state indemnity. ${ }^{13}$

Those aspects of the English model are uncontroversial insofar as they make the register reliable in favour of a purchaser who checked the register to confirm title before taking a disposition: they give effect to a policy of easing the land transfer process by simplifying investigation of title, increasing predictability, and reducing transaction costs. But the English model takes a rather more controversial step when it appears to offer the assurance of reliability to others as well. It is far from apparent what interests are being promoted by giving a guarantee to someone who is not a prospective purchaser in need of reassurance that the current proprietor has good title to the estate. To the extent that the assurance of reliability is given to people who look at the register for other purposes, the operation of the system demands confirmation and explanation.

Two case examples will be noted in order to indicate the way in which the system has been applied. The first is an early case typifying a classic situation. In $R e 139$ High Street, Deptford, ${ }^{14}$ Dobkins bought an unregistered shop, neither the contract nor conveyance referring to any plan. The seller and buyer believed the land to include an annexe which was in truth owned by BTC. Dobkins became first registered proprietor of the shop and by mistake the registry included the annexe. The court ordered removal of the annexe in rectification proceedings, but Dobkins was subsequently awarded indemnity. ${ }^{15}$ The case prompts a troubling question: on what principle could it be right to open up the possibility of resisting rectification, or awarding indemnity, when Dobkins had caused his own misfortune by not properly investigating the title to the unregistered land? The result enabled to Dobkins to gain from registration when he could not have relied on the register as a source of information at the time of purchase. Even if Dobkins had never expected to acquire the annexe, the outcome would presumably have been the same: indemnity would have been available and the

$9 \quad$ LRA 2002, ss 29 and 30.

10 LRA 2002, sch 4 (discretion in rectification) and sch 8(1)(a) (indemnity claim).

11 See DJ Hayton, Registered Land 3rd ed (Sweet \& Maxwell, 1981), p.180; EJ Cooke, The New Law of Land Registration (Hart, 2003) pp.125-127; E Lees, 'Title by Registration: Rectification, Indemnity and Mistake and the Land Registration Act 2002' (2013) 75 MLR 62; A Goymour, 'Mistaken Registrations of Land: Exploding the Myth of Title by Registration' [2013] CLJ 617.

12 'The factor which should carry most weight in the circumstances of the present case': Kingsalton Ltd $v$ Thames Water Developments Ltd [2001] EWCA Civ 20 para 52 (Sir Christopher Slade), a decision under the LRA 1925.

13 E.g. E Lees, 'Title by Registration: Rectification, Indemnity and Mistake and the Land Registration Act 2002' (2013) 75 MLR 62, 75, describing the pressure exerted by the Human Rights Act 1998, s 3, to interpret the legislation so as to make indemnity available here in order to comply with Article 1, Protocol 1 of the Convention.

$14 \quad$ Re 139 High Street, Deptford [1951] Ch 884.

15 TBF Ruoff, An Englishman Looks at the Torrens System (Law Book Co, Sydney, 1957) p 91, decided under the LRA 1925. 
result would have be even more surprising as he would have been compensated not for dashed hopes but for having failed to keep an unanticipated windfall.

The second example comes from Totton and Eling Town Council v Caunter. ${ }^{16}$ The defendants successfully claimed adverse possession before the adjudicator and they were entered as new proprietors. On appeal, the decision was reversed and the court ordered that they be removed as proprietors. It was decided that this order for removal amounted to rectification of the register. But on what principle could it be right to open up the possibility of declining to rectify against the Caunters, or to award them indemnity, when they were perfectly well aware that the decision of the adjudicator was liable to appeal and that their entry was accordingly susceptible to reversal pending the appeal outcome?

To confer protection on Dobkins and the Caunters in such circumstances appears to lack any sound justification. In neither case is it possible to point to the promotion of any market interest, such as maintaining confidence in security of receipt or facilitating transaction behaviour. At first glance it seems preposterous that a former owner might be denied recovery of the land because of an error on which nobody had ever relied; on the other hand, if the error were rectified (as indeed happened in both cases) it is doubtful that the defendants' subsequent indemnity claim could be ruled out by any contribution to the mistake and yet an indemnity award appears to be an unwarranted burden on the indemnity fund contributors. The decisions in these cases gives registered land participants a measure of protection which appears inexplicable. It seems to confer an unmerited and unexpected windfall at the expense of the former owner or the indemnity contributors. This approach of either upholding the error or compensating for it would be unthinkable in many other jurisdictions. In Scotland, for example, recent legislation ensures that these mistaken entries will be removed administratively without any prospect of declining rectification or offering compensation. ${ }^{17}$ Clearly there is a need to identify what policy drives the opposing view that is found in the English cases.

\section{B. Towards an Explanatory Proposition}

Two superficially attractive explanations for the provisions must be rejected before passing on to one which appears to fit the case. The first false effort at explanation is that the reliability of the register (in the sense of protection stemming from the ability to resist rectification or claim indemnity) is in these cases part and parcel of the principle which underlies the principle of statutory vesting of title and thus pursues the same purposes. The vesting principle, which confers title merely by entry as proprietor whether or not mistakenly ${ }^{18}$, serves the special purpose of identifying the locus of the legal estate to the benefit of those who might need to know for the application of legal doctrines which hinge on it such as merger. ${ }^{19}$ That special purpose is pursued regardless of whether an entry is liable to be rectified. It therefore operates

16 Totton and Eling Town Council v Caunter [2008] EWHC 3630. Compare Chief Land Registrar $v$ Franks [2011] EWCA Civ 772 which implies that alteration could be achieved by a restoration order under the Civil Procedure Rules 1998 r 52 without being troubled by the constraints of rectification. For correcting, setting aside and appealing tribunal decisions, see Tribunal Procedure (First Tier Tribunal) (Property Chamber) Rules 2013 rr 51-55.

Land Registration etc (Scotland) Act 2012, ss 80 and 85.

LRA 2002, s 58.

'Royal Commission on the Land Transfer Acts: Second and Final Report of the Commissioners' (1911, Cd. 5483), para. 30, responding to Capital \& Counties Bank Ltd v Rhodes [1903] 1 Ch 631. 
independently of rectification and indemnity, and consequently cannot explain why anyone should be able to resist the prospective reallocation of title through rectification or claim indemnity.

A second inadequate effort to account for extending protection to those who did not rely on the register to inform a decision to acquire could be based on its effect in facilitating the conveyancing process. ${ }^{20}$ This can be demonstrated through the illustration of a purchaser who fears that the seller might have stolen the identity of the registered proprietor. In these circumstances, although the assurance of reliability is being given to a prospective purchaser, it is not an assurance that the seller has a good root of title; instead it is an assurance that the purchaser, once registered, will be able to rely on his own registration. In this regard it is not a case of the purchaser relying on the register as a source of title information, because the register simply could not have been relied upon by the acquirer for the specific purpose of verifying identity and confirming the validity of the seller's forged disposition. ${ }^{21}$

A registration system could be designed so that the rectification and indemnity clauses provide the means of sustaining the reliability of the register in the event that the victim whose identity was stolen seeks to reverse the entry. The English model appears at first glance to adopt this technique: reliability is not generally promised to all prospective purchasers from the moment of inspection, but instead is deferred until the moment of registration, when the purchaser qua proprietor may then invoke the guarantee of reliability in respect of any disturbance to his status - whether stemming from a defect in the former proprietor's root of title or a defect in the immediate disposition to himself. This design could tend to discourage conveyancers from indulging in excessive measures to verify the seller's identity which are costly, delaying, ultimately inconclusive and might jeopardise the deal. The rectification and indemnity clauses which create the assurance of reliability could therefore be attributed the policy of facilitating conveyancing. However, that policy basis is rejected for two reasons. First, it cannot be sustained in the face of opposing influences elsewhere in the conveyancing system which demand investigation of identity, including the conveyancer's duties of care and loyalty to the purchasing client, registry standards ${ }^{22}$, professional guidance ${ }^{23}$, as well as imperilling the entitlement to rectification and indemnity for 'lack of proper care'. ${ }^{24}$ This reflects a pattern of contemporary anti-fraud measures internationally, for apart from a passing

20 R Sackville, 'The Torrens System - Some Thoughts on Indefeasibility and Priorities' (1973) Australian LJ 526, 531; M Neave, 'Indefeasibility of Title in the Canadian Context' (1976) 23 Univ Toronto LJ 173, 192. Contrast the view that it would reward carelessness: W Taylor, 'Scotching Frazer $v$ Walker' (1970) 44 ALJ 248, 254.

21 The classic observation comes from Gibbs v Messer [1891] AC 248, 255 (Lord Watson): 'Those who deal, not with the registered proprietor, but with a forger who uses his name, do not transact on the faith of the register.' Once registered, however, they may well do subsequent acts on the faith of the register entry which confirms their status as proprietor.

22 Land Registry Practice Guide 67 'Evidence of Identity' 2010 (England).

23 E.g. Law Society Practice Notes, 'Property and Registration Fraud' (2010) and 'Mortgage Fraud' (2014); SRA, 'Warning Notice on Bogus Law Firms and Identity Theft' (2012).

$24 \quad$ LRA sch 4 para 3(2)(a); LRA sch 8 para 5(1)(b). 
recommendation in Canadian reform policy ${ }^{25}$ there has been a strong recent trend of intensifying the onus of verification borne by the purchaser's lawyers. ${ }^{26}$

The second reason for rejecting that account of the rectification and indemnity rules as a source of reliability is that it is under-inclusive: it lacks the capacity to explain the full range of circumstances in which reliability is assured. The supposed rationale of facilitating conveyancing transactions can function only in a very limited range of circumstances, namely those involving a prospective acquirer who might have undertaken conveyancing investigations or some precautions (beyond investigating whether title vested in the named proprietor). The current English system does not separate out those circumstances for bespoke protection, instead they represent only an undifferentiated subset of the circumstances in which the assurance of reliability is currently available under the English statute. ${ }^{27}$ There remain many other instances where a beneficiary of a mistake in the register is able to invoke the assurance of reliability, such as the new proprietor who is mistakenly entered on the register without having consciously engaged in any acquisitive behaviour, such as a neighbouring landowner's disposition which the registry wrongly took to affect the proprietor's land, or a simple error in the registry's internal mapping change-over. ${ }^{28}$ No conveyancing precautions could be dispensed with here because no conveyancing activity was undertaken. To confirm the assurance of reliability in such cases, as the English statue does, therefore far exceeds the circumstances which could be explained by a policy of facilitating conveyancing.

A better explanation for the cases might be wrung from the role of the register in transmitting, creating and suppressing information. The register transmits pre-existing information that could be acquired less easily from other sources; insofar as it contains mistakes, it creates new information; and in relation to unprotected, precarious interests it has the capacity to suppress information and deprive it of legal effect in favour of a transferee for value. The communication of this information may have a causative effect on the thoughts and actions of the audience who encounters it. The information could induce expectations about ownership. This is the one and only effect that could always ensue from every type of mistake about title in the register. If a particular regime gives protection against the rectification of mistaken entries regardless of whether they have been relied on by a prospective acquirer to inform the decision to acquire, as the English model does, the only explanation for that protection which is dependent upon the unique institutions of registered land could be one which resides the register's effect of inducing expectations and the disturbance to plans that have been settled in reliance on the information gleaned from it.

For example, long after his acquisition the proprietor might inspect his own register to confirm the boundaries or the absence of covenants against building before developing the land. The protective rules which allow him to resist rectification or claim indemnity in the event of discovering a mistake are explained by the expectations induced in his mind by seeing the register's mistaken content, even if those expectations were induced only after initial purchase (as would be the case, for

\footnotetext{
25 Joint Land Titles Committee of Canada, 'Renovating the Foundation: Proposals for a Model Land Recording and Registration Act for the Provinces and Territories of Canada' (Edmonton 1990), para II G (6)(f)(iii), following the principle of cost-efficiency in conveyancing laid out by TW Mapp, Torrens' Elusive Title (Edmonton 1978 AILRR) p 132.

26 E.g. Land Transfer Bill 2010, cll 11 and 12 (New Zealand); Real Property Act $1900 \mathrm{~s} 56 \mathrm{C}$ (New South Wales); Land Titles Act (RSA 2000, c L-4) s 170 (Alberta).

27 E.g. Ajibade v Bank of Scotland [2008] EWLandRA 2006/0163 and Swift 1st Ltd v Chief Land Registrar [2014] All ER (D) 12 (indemnity for duped mortgagee following de-registration).

$28 \quad$ E.g. Safeway Stores Plc v Tesco Stores Ltd [2004] SC 29.
} 
example, when buying unregistered land and becoming first registered proprietor, when there can have been no reliance on the land register at the time of acquisition ${ }^{29}$ ). It is the protection of those expectations that justifies extending the assurance of reliability beyond prospective purchasers. Not only does that logic accommodate the utilitarian ideal of pursuing the result which inflicts the least anxiety on all concerned, it also advances the constitutional ideal of an opportunity to review state involvement in non-consensual transfer of property rights between citizens.

The proposed explanation of the protection against register mistakes through the rectification discretion and indemnity could also find normative support in the ideal of safeguarding investment in land. Before making expenditure in development works, the prudent proprietor may turn to the register to confirm the details of his title. If it cannot be relied upon to give an accurate picture of the state of title, the prospective development would be discouraged because of the possibility of wasting efforts on land that may have to be restored to another. To guarantee the reliability of the register here would serve to protect and encourage investment. It thus sits comfortably within the tradition that locates the origin of property in an artificial social convention to promote social utility, which has dominated modern thought since the rejection of divinely-instituted natural law as the origin of individual rights of property. It was famously expounded by David Hume ${ }^{30}$ who derived the virtue of property from its fulfilment of future expectations from current usage and explained from it the individual property law rules which connect the fact of possession to legal right, such as prescription, first occupation, and accession. ${ }^{31}$ His concentration on possession is perhaps unhelpful in justifying entitlements by force of a register entry, but he recognised that possession was not the final word and could be controlled by the broader principle of fulfilling expectation, as when he refers to property stemming from 'the sight of a thing, ${ }^{32}$, such as the rule that even a whole continent belongs to the nation which first discovered it. ${ }^{33}$ The strictly utilitarian account of property to serve economic ends - promoting investment - was advanced by Bentham who was prepared to extend Hume's lead by tying the expectations of protected investment not only to physical possession but also to the knowledge of abstract title:

'Everything which I possess, or to which I have a title, I consider in my own mind as destined always to belong to me. I make it the basis of my expectations, and of the hopes of those dependent upon me; and I form my plan of life accordingly. ${ }^{34}$

The standard teleological account of property, that its legal security encourages investment and discourages imprudent management by allowing the holder to reap what he has sown, is easily applied to the context of register reliability. That it was consciously perceived as one of the driving objectives of land registration is evident

29 RJ Smith, 'Land Registration: Reform At Last?' ch 8 in P Jackson \& D Wilde, The Reform of Property Law (1997, Ashgate Dartmouth, Aldershot) p143; 'Royal Commission on the Land Transfer Acts: Second and Final Report of the Commissioners' (1911, Cd. 5483), para 57.

${ }^{30}$ D Hume, A Treatise on Human Nature (London 1738 Noon), paras. 3.2.2.9 and 3.2.2.12.

${ }^{31}$ Hume, para. 3.2.3.5.

${ }^{32}$ Hume, para. 3.2.3.7, note 73 .

${ }^{33}$ Ibidem.

${ }^{34} \mathrm{~J}$ Bentham, Theory of Legislation (tr. Hildreth, London 1876 Stevens) p 115. Beyond settled possession, he includes property from first discovery of new islands ( $\mathrm{p} 159)$ and finding chattels $(\mathrm{p}$ 154). 
from the writing of Robert Torrens, champion of land reform in the Australian colonies:

'A very considerable extent of land which, but for doubts, for the most part upon mere technical points, affecting the title, would possess peculiar value as building sites, lie waste, receptacles of the offensive refuse of towns. If, by the operation of law, these defects could be cured, or the capitalist be assured against deprivation of the wealth expended upon the land, the vacant blocks which now disfigure the rising streets would immediately become available as building sites, and the wealth of the community be increased by the value restored to them as such.' 35

The justification for the assurance of register reliability which is made by this policy statement is one that is not restricted to prospective purchasers. It is equally relevant where the proposed form of reliance lies not in the payment of the price to a seller, but rather in the labour or expenditure on improvement of land already in the ownership of the developer, and therefore lends support to the explanatory proposition put forward to account for the wide remit of reliability under the English rectification and indemnity scheme.

\section{Inferences from the Explanatory Proposition}

The previous section proposed that the English model's approach to the reliability of the register was explained by protecting expectations that had been induced by the register's content. That proposition is put forward in order to explain the rectification and indemnity provisions outside of circumstances of reliance by a prospective purchaser. If it is to be accepted as an accurate description of the motivation behind the rectification and indemnity scheme, it can be used as the source for deductions about the due scope of protection. In particular, there are logical limits to the occasions when expectations ought to be protected, revealing that it is not necessary to go as far as the extravagant proposition that the information in the register should be guaranteed reliable in favour of all persons for all purposes.

First, because the protection of expectations is attributed to the practical effects on peoples' minds stemming from the register entry, the explanatory proposition is restricted to those whose expectations are induced by seeing or otherwise learning of the content of the register. There is no scope for protecting the person whose expectations about future enjoyment of property are generated by, for example, current factual enjoyment of the land. Even if expectations arising from such sources happened to coincide with the mistaken content of the register, they should not be protected if the person had never learned of the register content. Equally, the need for expectations induced by the register indicates that where a person has seen the mistaken register yet put no faith in its content, as when knowing of its mistaken nature, there is no scope for protection according to the explanatory theory.

Secondly, the protection justified by the presence of expectations induced by the register is relevant only to persons who would suffer by those expectations being thwarted upon rectification of the mistaken entry. There is no scope for protecting those who, on the contrary, would benefit from rectifying a particular entry. This

35 RR Torrens, The South Australia System of Conveyancing by Registration of Title (Adelaide 1859) p 26. 
leads to the proposition that the protection of expectations is restricted to those persons whose induced expectations from the register relate to their unwarranted holding of property rights. Protection of expectations explains why reliability is given only in favour of a privileged class of rightholders who have standing to resist an attack on the validity of the mistaken entry and not to others such as inquisitive neighbours. ${ }^{36}$

Those two limitations can be combined explicitly with the original formulation of the explanatory theory in order to create a general proposition about the approach of a coherent legislative scheme which incorporates the English model of rectification and indemnity provisions: when a right holder learns of a register entry which actually induces him to believe he has greater rights than those which would have existed in the absence of the mistake, the apparent state of his title should be made good by either declining rectification of the mistake or awarding indemnity. The remaining difficulty is that this proposition is not, however, entirely borne out by the operation of the system in practice. In particular, neither statute nor case law requires actual reliance as a precondition to resisting rectification or seeking indemnity. The empirical data, illustrated by the decisions in Deptford and Totton amongst many others, demonstrates that the presence of actual reliance on the register, and the expectations thereby induced, cannot be the explanation for having mistaken register entries upheld or indemnified. Further examination is required into how the explanatory proposition integrates with the seemingly discordant content of the statutory rules.

\section{Harmonising the Explanatory Proposition with the Observed Rules}

\section{A. Implementation by Proxy}

English registration law is capable of protecting proprietors against the reversal of entries in their favour even when there has been no actual sight of the register, and presumably even if they are entirely unaware of the entry. ${ }^{37}$ It is submitted that this departure from the explanatory proposition does not indicate that induced expectations have been rejected as the foundation for protecting proprietors from mistaken entries. Instead, it is submitted that expectations induced by the register constitute the reason for conferring protection, but that the deviation between the ideal of protecting expectations and the content of the legal rules is due to practical reasons of efficiency. It is submitted that it is out of convenience that the legislature has chosen to implement the policy of protecting induced expectations by using rough and ready proxy rules to stand in for induced expectations. The use of the proxies may obscure the policy underlying the protection afforded by rectification and indemnity, but does not displace it. Protection of induced expectations remains a convincing

36 There may, however, remain concerns that this restriction would exclude people seeking to avoid infringement of the proprietor's rights from obtaining easy access to reliable information on ownership, thus inefficiently increasing their information costs: see TW Merrill \& HE Smith, 'Optimal Standardization in the Law of Property' (2000) 110 Yale LJ 1, 26.

37 No reported judgment has been uncovered in which this has occurred, although it would be compatible with the cases summarised in TBF Ruoff, An Englishman Looks at the Torrens System (Law Book Co, Sydney, 1957) p 96, decided under the LRA 1925. It may be anticipated that most mistakes occur in processing a disposition, and nowadays the practice of automatically returning a printout to the new proprietor is likely to reduce the incidence of cases in which the proprietor did not have the register information at his disposal: Land Registry Public Guide No.3 (Nov 2012) para 3. 
explanation for the scheme so long as it is understood that the rules effectuating it represent a compromise between perfect targetting at their policy objective and convenience in their administration.

The rules for introducing the discretion to refuse rectification and award indemnity are contingent on one criterion: a mistake ${ }^{38}$ (one which can be corrected by alteration of the register, ${ }^{39}$ implying that it must be a mistaken entry in the register) whose correction would prejudicially affect the title of a registered proprietor. ${ }^{40}$ That is all that is necessary for a proprietor to prove in order to be eligible to resist rectification proceedings or claim indemnity. It deviates from the pure ideal of protection in that it does not require the mistaken entry to reach the proprietor and induce an expectation that he would retain the benefit of the entry. But to fulfill the ideal in a perfectly targetted fashion by insisting on proof of induced expectations would involve extraordinarily costly processes, including proof of a range of difficult facts: that the proprietor or his agent had sight of the mistaken register, or the content of the register had come to his attention via an intermediary or via hearsay reports through however many hands; that any hearsay report of the mistaken entry was narrated accurately and comprehensively; that the proprietor had appreciated the import of the mistaken entry; that the proprietor had formed an expectation that he would retain the property which the register mistakenly represented as his; that the expectation was sufficiently developed and convincing in his mind; that the proprietor's expectations were causatively connected to the content of the register; that the proprietor did not disbelieve the register entry or doubt the veracity of the media by which the information was indirectly conveyed. In addition there might be costs associated with argument over legal issues such as the burden of proof and the existence of minimum legal thresholds such as the reasonableness of a proprietor's alleged subjective expectations.

Such inquiries as these are eliminated at a stroke by tying the availability of protection to the crude factual question of whether the register bore a mistaken entry. ${ }^{41}$ The only remaining issues for costly inquiry are compact legal questions over interpretation of mistake and prejudice to title, for which there is limited scope to propose competing interpretative theories. By adopting this approach to rulemaking, the rectification and indemnity scheme effectively concerns itself not with the actual existence of induced expectations, but instead focusses merely on the opportunity to induce expectations in a proprietor. Although the statutory rules may ultimately overprotect, as where rectification is declined or indemnity awarded to a proprietor who never relied on the mistaken entry, hearing of it for the first time when the registry forwards the notification of the rectification claim, this over-protection must be understood as the lesser evil conceded by the legislature in order to employ costefficient short cuts that occasionally miss the target.

\section{B. Actual Reliance and the Discretion to Decline Rectification}

Although the proof of induced expectations may be perceived as too costly an exercise to insist on as a precondition to protection, there is nothing to preclude

LRA 2002, sch 4 para 2(1)(a).

LRA 2002, sch 4 para 2(1).

LRA 2002, sch 4 para 1(b).

D Baird \& T Jackson, 'Information, Uncertainty and the Transfer of Property' (1984) 13 Journal of Legal Studies 299, 319-20 (recognising the costs associated with proof of reliance in filing systems). 
parties from raising it in rectification proceedings. Once the rectification power is engaged by the existence of a mistake whose correction would prejudice title, the decision whether or not to rectify will rest on discretionary standards - in particular, whether there are exceptional circumstances to warrant upholding the mistaken entry or whether it would be unjust not to rectify it. ${ }^{42}$ The rectification proceedings can therefore be used as the forum to look into wide-ranging issues of fairness between the parties. Either litigant in the rectification proceedings is free to make the case that there was or was not inspection of and reliance on the erroneous register. The mere opportunity for reliance outlined above is therefore far from determinative of whether rectification will be declined, and the rectification scheme's connection to actual induced expectations is reinforced by evidence that in rectification proceedings the courts have consistently allowed an inquiry into actual reliance.

The courts have demonstrated a willingness to explore factual material relating to the defendant's knowledge of and reliance on the mistaken entry. For example, the court has accepted that in exercising the rectification discretion it would be a 'critical matter' to assess whether the defendant believed that the entry on the register conferred good title on him. ${ }^{43}$ Cases have also disapproved of proprietors resisting rectification where it would give an 'undeserved and unbargained for windfall' 44 or confer land "which it never intended to acquire and which is of no use to it save as a means of extracting a ransom payment from James Hay [the former owner], a stance which however legitimate commercially does not commend itself to this court as in any way meritorious ${ }^{45}$, indicating a desire to correlate the rectification outcome to the expectations of the proprietor benefitting from the mistaken entry. ${ }^{46}$

Where the defendant from the outset was aware of the mistake in the entry, then reliance is likely to be negated by that knowledge and the courts correspondingly unwilling to protect the proprietor. For example, in one case a factor pointing in favour of rectification was that the defendant 'knew there was a dispute which he did not disclose to the Land Registry. All of the acts of possession and expenditure relied on by Mr Moore were carried out in the teeth of objections by Mr Saxon and in the full knowledge of the dispute. ${ }^{47}$ In another case, emphasis was placed on the defendant's actual knowledge of the mistaken omission of an entry in reaching the court's decision to rectify against him. ${ }^{48}$ In yet another case, one of the factors in favour of granting rectification was that 'The claimant knew, or ought to have known, that she had no paper title to the axe-head [the disputed land]. A glance at her own conveyancing documents would have told her that. ${ }^{, 49}$ Collectively they signify that knowledge of the mistaken nature of an entry is a factor tending against reliance when the mistaken entry should not be upheld.

On the other hand, there has been some recognition that induced expectations are not necessarily incompatible with knowledge or suspicion that the status of the entry might be controverted. It comes from a judgment in rectification proceedings brought under the Land Registration Act 1925 against joint purchasers who bought after

\footnotetext{
$42 \quad$ LRA 2002, sch 4 para 2(1)(a). Land Registration Rules 2003, r 126 applies a similar test for correction in cases of mistake which does not amount to rectification. Paton v Todd [2012] EWHC 1248 para 90 (Morgan J). Horrill v Cooper (1999) 78 P\&CR 336 (HHJ Colyer at first instance). James Hay Pension Trustees Ltd v Cooper Estates Ltd [2005] EWHC 36 para 41 (Hart J). Followed in Sainsbury's Supermarkets Ltd v Olympia Homes Ltd [2006] 1 P\&CR 17 para 94 (Mann J). Saxon v Moore [2005] EWHC 27 para 94 (HHJ Behrens). Rees v Peters [2011] EWCA Civ 836 para 24 (Morritt C). Johnson v Shaw [2003] EWCA Civ 894 para 48(3) (Peter Gibson LJ).
} 
having inspected the register, but the comments are expressed sufficiently broadly to cover non-purchaser cases. It was said that one of the "crucial factors' ${ }^{50}$ was that the purchasers were 'entitled to assume that their title would be afforded the protection normally afforded to the title of registered proprietors in possession - and no less so because they knew that before the title of their predecessors, the Mayhews, was registered, there had been doubts as to the true boundaries of the disputed land. The very purpose of registration was to resolve such doubts. ${ }^{51}$ The extract suggests that in rectification proceedings the court is willing to entertain submissions which scrutinise the subjective expectations and state of mind of the proprietor who had inspected the register with a view to establishing induced expectations.

\section{Actual Reliance and the Award of Indemnity}

As with protection through the exercise of the rectification discretion, the award of indemnity is not dependent on proof of any form of reliance on the register: without reference to induced expectations, indemnity is available to any defendant against whom rectification proceedings are successfully brought. It can be explained as accepting proof of the mere opportunity to have seen a mistaken entry as a handy proxy standing in for the complexities of actual reliance on a mistaken entry. The result is that indemnity is payable even in cases where the proprietor did not rely on the register or know of the mistaken entry.

In many typical cases, indemnity will be withheld or reduced in these circumstances due to the rule applicable when the loss is suffered by the claimant wholly or partly 'as a result of his own lack of proper care'. ${ }^{52}$ The loss of indemnity due to carelessness does not, however, precisely equate to absence of reliance on the register. A good test scenario is that of rectifying an unexpected windfall. According to Ruoff, indemnity has been awarded in a number of instances where:

'the benefit of an easement has been unwarrantably or mistakenly entered as appurtenant to an owner's registered land. This has usually occurred on the occasion of the transfer of part of the land in a title. When, later, it has been found that the vendor did not grant, or did not have the power to grant the easement in question, the benefit of it was removed from the registered title'. ${ }^{53}$

If indemnity is to be awarded in those cases, then it would be difficult to see how the award of indemnity could be any different in the event that the entry of the unwarranted rights occurred after the acquisition rather than contemporaneously with it, and if the proprietor never expected to acquire them, and if indeed the proprietor was entirely unaware of their entry. There is even authority implying that proving the absence of any reliance does not take away indemnity. In Dougbar Properties Ltd $v$ Keeper of the Registers of Scotland ${ }^{54}$ the register mistakenly conferred car parking

$50 \quad$ Kingsalton Ltd v Thames Water Developments Ltd [2001] EWCA Civ 20 para 57 (Sir Christopher Slade), a decision under the LRA 1925.

Ibid.

LRA 2002, sch 8 para 5.

TBF Ruoff, An Englishman Looks at the Torrens System (Law Book Co, Sydney, 1957) p 96 (Case 4) decided under the LRA 1925.

$54 \quad$ Dougbar Properties Ltd v Keeper of the Registers of Scotland [1999] SCLR 458 (decided under the Land Registration (Scotland) Act 1979 resembling the provisions of the English LRA 1925). It involved a prospective purchaser, but the point raised in it would be equally relevant to any other persons to whom the assurance of reliability was given. 
rights on the proprietor of plot A. Dougbar, knowing of the mistaken inclusion, bought plot $\mathrm{A}$ and, when the register was corrected, claimed on the state guarantee. The court upheld the award, finding that Dougbar knew of the mistaken nature of the entry, and would not be barred from indemnity on the ground that it had contributed to the loss by its lack of care.

In Ruoff's cases and Dougbar, the claims to indemnity are strikingly unmeritorious: they compensates the proprietor for failing to retain an adventitious bonus from the registry's oversight which was never due to him, which he never sought or expected to acquire, and which he had no expectation of retaining. But results such as those are inevitable if the indemnity clause is to be explained as protecting reliance through an imperfect but convenient proxy which sidesteps the need for proof of induced expectations.

The explanatory account of the striking results coming out of rectification and indemnity cases has been premised on the use of proxies which are justified by cost efficiency. If that represents the legislature's thinking, it merits an empirical inquiry into the supposed cost effectiveness of the trade off. Every time indemnity is paid out to a proprietor who did not rely on the erroneous register entry, it devotes resources to unnecessary payments that advance no policy objective. While the payment of market-value indemnity to proprietors who, as prospective purchasers, relied on the register is always justified in order to facilitate conveyancing and preserve market confidence in registered land, the same compelling policy objective does not apply to the other circumstances in which indemnity might be claimed following rectification. For the latter, there should be an assessment of whether subsidising market value indemnity in the absence of reliance truly represents good value for money through the social cost saving that results from the simplified indemnity claims administration. If not, other options are open to the legislature: indemnity could be withheld unless the claimant could demonstrate an actual induced expectation of retaining the property or perhaps actual knowledge of the mistaken entry ${ }^{55}$ Alternatively, an even more restrictive regime, stopping short of deferred indefeasibility, could depend on the claimant demonstrating the same condition of reliance, but then restricting the indemnity award to a sum equal to the detriment, if any, that had been suffered by having relied on the mistaken entry. The latter measure of indemnity would effectively uproot the role of indemnity in securing the fulfilment of expectations and replace it with the limited role of reimbursing reliance expenditure.

\section{The Limits of Expectations}

This part explains how the fulfilment of induced expectations by proxy as the proposed explanation of the rectification and indemnity scheme might interact with other moral and legal factors affecting land registration.

\section{A. Moral Principles}

It was posited that the mere opportunity for induced expectations stands as a proxy for actual induced expectations in the legislative scheme and was potentially advancing a policy of efficiency in rule administration. It was not empirically substantiated, but merely put forward as a plausible justification for the statutory scheme. While the

55 The approach taken by Scottish Law Commission, 'Discussion Paper on Land Registration: Void and Voidable Titles' (Discussion Paper No.125 Edinburgh 2004) paras 3.15 - 3.41. See Land Registration etc (Scotland) Act 2012 s 85. 
proxy might imbue the system with a greater degree of efficiency, it is incapable of responding to the influence of any external moral forces. There may be occasions when the proprietor who benefits from a mistaken entry ought not to be able to take advantage of it. In particular, a moral duty may arise on that proprietor to protect others by taking precautions to minimise the loss caused by the mistaken entry. Such a moral duty might be attributed to the prevention of anti-social conduct, whether on grounds of selfishly exploiting the mistake in a way that exacerbates the losses inflicted on others, or on grounds of economic efficiency in wastefully passing up the cheapest way to avoid embroiling the parties in a priority dispute.

No such duty should be recognised where the proprietor has no actual subjective doubt over the validity of the register entry, for the imposition of the duty would then encourage investigations into the validity of the title information that would conflict with the very motive for introducing the registration system. But the potential moral duty is implicated where the proprietor is aware of facts from which he forms the view that the register entry ought not to be relied on. Some jurisdictions have explicitly denied protection in these circumstances by insisting on proof of a belief that the entry was authorised and no knowledge of the facts that rendered it unauthorised, ${ }^{56}$ but there is little in the English model of registration from which to mount any argument that would prevent the proprietor in these circumstances from claiming protection through resisting rectification and thereby casting the loss on the former landowner, or from claiming indemnity and passing the burden to the indemnity fund contributors. The moral objection to vindicating the register content might be factored into the discretion available in rectification proceedings, but so long as indemnity is barred only by contribution to the error, and not to exacerbating its effects, then the proprietor stands to gain from reprehensible conduct.

Moral objections to the unmitigated effects of the proxy are already reflected in certain legal doctrines. Wherever the supposed policy of fulfilling a proprietor's expectation of retaining the registered rights appears to transgress such an external legal rule, it becomes necessary to identify which must give way to the other. Two potentially conflicting legal rules demand consideration: the rule of chronological priority for unprotected, precarious interests ${ }^{57}$, and the rule permitting rescission of voidable dispositions.

\section{B. Precarious Interests}

The proposed explanation for the rectification and indemnity scheme is founded on the protection of the expectations of those who have inspected, or who had the opportunity to inspect the mistaken entry in the register. It is possible to imagine circumstances in which this supposed protective function could collide with the basic rule that the priority of precarious interests vis-à-vis other interests is to be determined by their chronological order. ${ }^{58}$ For example, if the proprietor were to grant an option to purchase, which the optionee protected but the registry mistakenly deleted, then the

\footnotetext{
56 E.g. Land Registration Act $(2001$, c 6) s 35(7) (Nova Scotia) and Métis Settlements Land Registry Regulation (Reg 36/1991) r 34(1) (Alberta). The Foreign and Commonwealth Office's model statute for title registration in the colonies was intended to restrict indemnity to entries pursuant to an intended disposition: SR Simpson, Land Law and Registration (CUP Cambridge 1976) p 596 (making an all too subtle distinction between 'damage' and 'loss').

57 I.e. those interests which, if unregistered, are liable to cede priority to a registered transferee under LRA 2002 ss 29 or 30.

LRA 2002, s 28.
} 
proprietor might long afterwards review the register to confirm his title before investing in development of the land, having forgotten the existence of the option. ${ }^{59} \mathrm{In}$ these circumstances, the supposed policy of protecting the expectations of a proprietor who relies on the register otherwise than for informing a decision to buy would entail that the proprietor be able to resist the optionee's rectification proceedings or claim indemnity. To protect the proprietor in that fashion would deny the enforcement of the option. No doubt the response in those circumstances could be managed by enforcement through contract law, thereby sidelining any question of rectifying the register. That solution would not, however, apply if the example were altered from the grant of an option to the grant of an easement to a donee with no overlying contractual relation. Short of some remedial equitable intervention to create an obligation out of the omitted easement, the supposed policy of protecting the proprietor's expectations would appear to remain intact, despite its intuitively repugnant consequences in defeating the granted easement. This is a case in which the supposed policy would be in tension with the policy of preserving the enforceability of rights against the grantor.

The solution through in personam obligations such as contract would be equally unavailing if the land had passed to a new proprietor otherwise than for valuable consideration, such as the heir of the original grantor. The policy of preserving the priority of precarious interests according to chronological order would apply here, but in these circumstances there is a rather stronger justification for protecting the proprietor's expectations. The heir might have few leads to follow in seeking offregister information on title, yet might require perfectly sound title before committing expenditure to investment in the land. Without an assurance of reliability of the register, the heir would be discouraged from improvements without wide-ranging and inconclusive inquiries into potential outstanding precarious interests. Offering protection to the heir's reliance on the register in these circumstances would at least serve the purpose of removing the incentive to incur title investigation $\operatorname{costs}^{60}$, but it nevertheless remains in tension with the policy of preserving the priority of precarious interests against all but a transferee for value.

The field in which these opposing arguments will be tested is probably to be found in the statutory definition of rectification, which requires that it 'prejudicially affects the title of a registered proprietor' ${ }^{61}$ This neglected phrase has not been the subject of significant commentary. There are alternative interpretative options. First, it might refer to derogating from the state of a proprietor's title as appearing from the register entries. Taking this approach, the proposed insertion of an unprotected precarious interest would constitute rectification, enabling the proprietor to mount a discretionary resistance to the alteration or claim indemnity, even though the interest was binding on the proprietor according to the priority rules. The proprietor would claim that the relevant form of prejudice was depriving him of the opportunity to represent a clear title to others, such as prospective purchasers, and seek to negotiate a price based on unencumbered ownership, even though he himself was bound and the unprotected interest would be defeated by the sale. That line of argument was rejected

59 There is little coherent jurisprudence on the failure of a right holder to forestall priority disputes due to his forgetfulness or failure of corporate memory: see Sinclair Investments (UK) Ltd v Versailles Trade Finance Ltd [2011] EWCA Civ 347 and William Sindall plc v Cambridgeshire County Council [1993] EWCA Civ 14.

60 TW Mapp, Torrens' Elusive Title (Edmonton 1978 AILRR) p 125; P O'Connor 'Registration of Title in England and Australia: A Theoretical and Comparative Perspective' in E Cooke, Modern Studies in Property Law vol. II (Hart 2003 Oxford) p 91.

61 LRA 2002, sch 4 para 1(b). The first modern case to raise it has just appeared: Swift 1st Ltd v Chief Land Registrar [2014] All ER (D) 12. 
in Attorney-General $v$ Odell ${ }^{62}$ under a forerunner of the modern legislative provision. ${ }^{63}$ It is submitted that argument should be similarly rejected under the current legislation. ${ }^{64}$ It would not only have preserved the informational asymmetry between the proprietor and buyer which he had hoped to exploit, but it would more generally impede the mission to increase the comprehensiveness of the register as a record of rights. ${ }^{65}$

The second interpretative option would be that proprietor's plea of 'prejudice to title' must refer to a proposed change to the register which derogates from the priority rules established elsewhere in the Act (particularly the basic and special rules). In the context of precarious interests, the insertion of such an interest which was already binding on the proprietor according to the priority rules would not amount to rectification. This interpretation would therefore avoid the rectification jurisdiction altogether and consequently deny eligibility for indemnity. No doubt the precarious interest could still be inserted onto the register through the separate head of alteration that is available to 'bring the register up to date' and for which no indemnity is available. ${ }^{66}$ This route would avoid the criticisms aimed at the previous interpretation in Odell and would have the advantage of reflecting the actual allocation of entitlements in the land rather than the incomplete information about title that is revealed from the register which excludes unprotected precarious interests and overriding interests. This second interpretation of 'prejudice to title' would therefore provide the means to resolve the tension between the protection of the proprietor's induced expectations and the preservation of precarious interests in favour of the latter.

\section{Voidable Transactions}

The supposed policy of protecting the expectations of those who have inspected or who had the opportunity to inspect the mistaken entry in the register could also run into competition with the rule permitting rescission of voidable dispositions. For example, if a purchaser were to become registered pursuant to a disposition tainted by his undue influence, he might afterwards review the register to confirm his title before investing in development of the land, unmindful of the circumstances that rendered the disposition voidable. This scenario requires examination of whether such genuine reliance on a clear register should affect the status of the transferor's undisclosed right to rescind.

The mainstream approach is to regard a voidable transaction as not establishing a basis for rectification or indemnity, even once the victim has rescinded ${ }^{67}$ Instead, it would see the impeached disposition as effective to transfer ownership, categorising the rescission as a supervening event which changes entitlements. That analysis treats

\footnotetext{
62 Attorney-General v Odell [1906] 2 Ch 47, 75 (Vaughan-Williams LJ).

63 Land Transfer Act 1897, s 7(4) referring to the claimant 'suffering loss' by the alteration.

64 It has observed that this theory might, however, explain the decision in Rees $v$ Peters [2011] EWCA Civ 836: A. Goymour, 'Mistaken Registrations of Land: Exploding the Myth of Title by Registration'[ 2013] CLJ 617 note 112.

65 Law Commission \& HM Land Registry, 'Land Registration for the Twenty-First Century' Law Com. 271 (2001), para 1.5.

$66 \quad$ LRA 2002, sch 4 para 2(1)(b).

$67 \quad$ Norwich \& Peterborough Building Society $v$ Steed [1993] Ch 116, decided under the LRA 1925; Law Commission \& HM Land Registry, 'Land Registration for the Twenty-First Century' Law Com. 271 (2001), para 10.7(1), n 23. This is also the approach taken explicitly in Land Registration etc (Scotland) Act 2012 s 65(4).
} 
the event of rescission as the foundation for an application to bring the register up to date $^{68}$ which is all but mandatory. It has the effect of detracting from the reliability of the register, which would conversely be enhanced by ensuring that expectations induced by inspection are protected through allowing the proprietor to resist rectification or recover indemnity. This effect is the origin of a minority critical approach which would insist on running the reversal of voidable grants through the discretionary power of rectification by classifying the entry of the defective disposition as a statutory mistake from the start. ${ }^{69}$ Despite the authority of the joint report of the Land Registry and Law Commission ${ }^{70}$, the courts have so far been cautious to avoid choosing between the mainstream and critical positions. ${ }^{71}$

The central issue over voidable dispositions of registered land is whether the policy of protecting the immediate recipient's reliance on the register should ever be able to trump the policies which justify rescission; if so, the disponor's claim to rescind must be governed by rectification and the disponee must be given the opportunity to raise the discretionary factors in the rectification proceedings. Had the recipient himself been implicated in creating the circumstances leading to the impairment of the disposition, no doubt this would be a powerful factor in the exercise of discretion and would also block indemnity due to the contribution to the error, since even the amoral register should not tolerate the outrage of an oppressor gaining by his oppression. But where the vitiating factors arose from another source, a policy decision must be taken. On the one hand, the goal of protecting the vulnerable, which lies at the heart of voidable dispositions, suggests that there is, at the least, a conceivable policy in favour of limiting the extent to which register-based expectations should be upheld. On the other, there is the purity of the disponee's honest forgetfulness, albeit with an eye to the obvious moral hazard of misrepresented mental state. These are the considerations which must ultimately influence the decision whether the disponor's claim is allocated to discretionary rectification or administrative updating.

\section{Conclusion}

This chapter has attempted to dispel the air of puzzlement over a registration system which, in the event of an erroneous entry, appears to confer the right to claim compensation for its loss or resist its reversal to a person who was not expecting it, never relied on it, did not plan affairs around it, and perhaps never even knew of it. The answer lies in a defensible policy of fulfilling expectations induced by the register, coupled with a practical concession to convenience by employing proxy rules for the implementation of this policy, thus confirming that is quite inadequate to explain the current model of land registration in England as a purchaser's system. Proxy rules have an important place in property law. Their ability to provide a simple route to a predictable result strikes a chord with the aspirations of land law in providing ex ante certainty of entitlement which enables people to plan investment in

$68 \quad$ LRA 2002, sch 4 para 2(1)(b).

69 PJ Clarke, 'Registered Land' [1993] All ER Rev 242, 246; C Davis, 'A Restrictive Approach to Rectification' [1992] Conv 293, 297.

70 Law Commission \& HM Land Registry, 'Land Registration for the Twenty-First Century' Law Com. 271 (2001), para 10.7(1), note 23.

71 Baxter v Mannion [2011] EWCA Civ 120 para 31 (Jacob LJ), 'I would reserve my position'; Garwood v Bank of Scotland plc [2012] EWHC 415 paras 70 - 72 (Norris J), 'I do not have to decide this issue'. Under the New Zealand reforms, the reversal of voidable dispositions will be governed by discretionary rectification: New Zealand Land Transfer Bill 2010, cl 13. 
land with confidence. But there are two important caveats: the use of proxy rules must not conceal the policy objectives which underlie them so as to risk leading the interpreter astray, and in simplifying the implementation they must not deviate too far from their underlying policy objectives with a counterproductive result. This chapter has shown that there is reason to object on both counts to the English provisions for rectification and indemnity.

First, it was argued that those provisions were explicable only by the policy objective of fulfilling the expectations that had been induced by knowledge of the register content. The obliqueness of the statutory text from which this was inferred is demonstrated by contrasting it with the elegant form of assurance in Scotland, which overtly recognises that register entries are guaranteed in favour of particular persons for particular purposes and it is a fallacy to think of register information as reliable in the abstract: 'The Keeper, in accepting an application for registration, warrants to the applicant that, as at the time of registration, the title sheet is accurate...' Secondly, it was argued that the rectification and indemnity provisions deviate significantly from the underlying policy objective due to their embodiment as ill-fitting proxy rules. This is particularly dangerous for property as it might uphold the rights of a mistakenlyentered new proprietor who falls within the proxy rules but outside the policy objective underpinning them, and might therefore expropriate the former proprietor without any justification other than the convenience of having rules that are easy to administer.

This chapter has dwelt on the issue of the operation of and justification for the rectification and indemnity provisions in relation to persons other than prospective purchasers seeking a good root of title. This naturally invites a review of the wider impact of protecting the register-induced expectations of all registered proprietors even though they could not or should not have relied on the entry. The current policy of protecting such a wide constituency of actors weighs heavily on the indemnity fund contributors and has the capacity to destroy conflicting property rights where the justification for doing is distinctly weak - for example, in order to fulfil expectations that were induced by sight of the register but were not actioned by any expenditure or behaviour in reliance. To excise the most extreme examples, the legislation should at least adopt a pared down version of the assurance of reliability which would compensate only reliance losses flowing directly from expectations induced by the register, and possibly also refuse relief in the cases of oppression embodied in the law of voidable transactions. Given the contemporary sensitivity to the pressures on the compensation fund and to the constitutional propriety of expropriating private owners, an even more robust response would rebalance social priorities so as to focus protection exclusively on purchasers. Reform need not halt there: far from the past reform ambitions of easing their conveyancing investigations in the interests of efficient market allocation of land, future reform should recognise the strength of the compensation and constitutional arguments of the current environment in justifying the costs of higher standards of diligence on purchasers - such as more onerous steps for identity verification - as a precondition to their benefitting from the assurance of reliability. 